The abdomen was opened by the rectal-sheath method. There were extensive adhesions of the smiall intestine. The condition videnced severel attacks of localised peritonitis. During search for the appendix a loop of small intestine presented itself ; as the latter was brought through the abdominal ineision a circular ulcer perforated, but was rapidly dealt with. Passing the hand into the left iliac fossa one felt the bladder with an enlarged prostate drawn over towards it by adhesions to bowel, and by adhesions of bowel to parietal peritoneum. These were separated, and the bladder resumed its normal position. Searching for the appendix I then found that there was a complete transposition of the large bowel. The ileum ended in the crecum on the left side of the abdomen, the cæcum boing continued up on the left side as the ascending colon, passing into the transverse colon, and thus descending on the right side as the descending colon. At the level of the iliac crest the descending colon passed at an acute angle to the centre of the brim of the true pelvis to descend as the ansum. rectum. A remarkable feature was the absence of the sigmoid bile-du. I examined the gall-bladder, and cystic, hepatic, and bile-ductsand found no evidence of gall-stones. There was no time had a temperature during his attacks.

Recovery after the operation has been rapid. The facts here stated will be corroborated by Dr. Douglas P. Blair and Dr. J. Dunn, who were present at the operation.

\section{A CASF OF}

NERVE SUTURE WITH IMMEDIATE RETURN OF SENSATION.

By William Robertson, M.D. Glasg.

THE reference in THE LANCET of July 24 th to denervated muscle recalls a case I had to deal with some time ago, of which the following is a brief clinical account:-

In 1897 a boy, aged 11 , fell from his pony, sustaining a compound fracture of the left humerus near the elbow. The boy cried out and a kaffir pulled the injured arm rather roughly. The sharp edg of the fractured humerus could be easily seen in the wound. No attention at the moment was paid to the innervation of the arm owing to the extensive wound in front of the joint and the settin of the fracture. The limb was put up in rectangular splints. Th wound healed rapidly and early movement could be practised. It was soon noticed that atrophy of the forearm and hand was too extreme to have been caused by the mere splinting of the limb, and sensation was bad in the fingers. One night the forefinger cam accidentally in the candle and was burned without the patien being aware of it. After the wound was healed the bone united and the joint was mobile. An incision was made over the median nerve some distance above the site of the fracture. Abundant cicatricial tissue was met with enveloping the nerve. After freeing the nerve from this the sheath was found to be intact, but on running the finger along a sap was observed indicating the complete severance of the nerve within its sheath, the gap measuring perhaps 2 or $3 \mathrm{~mm}$. The sheath was cut through the gap, and when the two cut ends of the nerve were examined each surface was found covered with small oval bodies, the repair material of a severed nerve. No formed tissue existed between the ends of the nerve. The repair material was shredded off down to normal nerve fibre, and the two ends of the nerve were sutured through with fine silk, In opposing the ends the proper aligninent of the nerve was observed. The nerve sheath was carefully stitched up. When the boy came out of chloroform, or shortly afterwards, with an exclamation of surprise he told me he could feel his finger He could also discern articles placed between fingers and thumb.

The wound healed by first intention. The splint was continued and for a few weeks gentle daily movement of the elbow-joint was all that was attempted. To the integrity of the nerve sheath is to be attributed the early functioning of the nerve cells. The arm since the operation has given no trouble and is now perfect in function and strength. No doubt the nerve was severed inside its sheath by the rough pulling on the arm at the time of the accident.

Mossel Bay, South Africa.

LITERARY INTELLIGENCE.-Messrs. W. Heinemann "Gedical Books), Ltd., will shortly publish a new work on by Dr. Ll. Jones Llewellyn, to contain a section on Ocular Disease by Dr. W. M. Beaumont.

Complaints Against aN Insurance Mfoical OFFICER.-Complaints were recently made by two patients against a panel doctor in Devonshire, and the report of the committee of inquirs, which was held at Okehampton, was forwarded to the Ministry of Health. Dr. Addison has replied that he is not satisfied that the continuance of the medical officer referred to would be prejudicial to the efficiency of the medical service of the insured, and consequently will take no further action in the matter. One of the complainants was ordered to pay 2 guineas towards the costs of the medical practitioner, but as the other complainant was deceased no order would be made.

\section{Mtedical Soctetres.}

\section{ROYAL SOCIETY OF MEDICINE.}

\section{SECTION OF OBSTETRICS AND GYNACOLOGY.}

A MEETING of this section of the Royal Society of Medicine was held on Nov. 4 th, Professor HENRY BRIGGs, the President, being in the chair.

Dr. J. D. BARRIS and Dr. M. Donaldson presented a short communication on

\section{Acute Inversion of the Uterus: Treatment by Blood} Transfusion and Late Replacement.

Dr. Barris said that the patient, a housewife, aged 34 had been admitted to hospital on August 12th on account of collapse and hæmorrhage following labour.

She had been married for six years and twice pregnant; the first pregnancy had ended in miscarriage at the third month, September, 1914, and the second in labour at term, October, 1916, when she was delivered of a $10 \mathrm{lb}$. child without difficulty. The present labour, which was conducted by a midwife, began at 3 A.M. and a child weighing $7 \mathrm{lb}$. was born at 6.5 A.M. on August 12 th, the perineum being torn incom pletely. The placenta did not come away spontaneously, and after two hours the midwife delivered it by expression, at the same time pulling on the cord. Profuse hæmorrhage followed and the patient "felt something come down." On her admission to hospital at 5 P.M. she appeared blanched and collapsed. Temp. $98^{\circ} \mathrm{F}$., pulse 120. A swelling, identified as the uterus, was found rising to 41 in above the pubes, and in the position of the fundus a distinct cup-shaped depression could be felt. The vagina contained much fresh blood and blood clot. The fundus uteri could be felt projecting through the external os and lying just inside the vaginal orifice, and a diagnosis of acute inversion was made. It was decided to treat the patient for collapse and hæmorrhage and to postpone the replacement of the uterus. Pituitrin, $1 \mathrm{c.cm}$. was injected hypodermically and a hot vaginal douche was given. Two days later the red cells numbered 1,800,000 and blood transfusion was attempted (citrate method), but owing to a fault in the apparatus only $100 \mathrm{c.cm}$. could be introduced. The patient continued to bleed and on August 27th the red cells numbered only $1,200,000$. $600 \mathrm{c.cm}$. of blood were transfused on Sept. 3rd, and the number of red corpuscles rose to 2,570,000 on Sept. 4th. Local sepsis, evident within three days of admission, was treated by means of Carrel's tubes inserted into the vagina, using a solution containing 1 in 4000 pot. permang. and 1 per cent. sod. sulph. The irrigation was continuous, and so regulated that if the pads were changed every three hours the bed remained dry. On August 18th, during micturition, the fundus became completely inverted and protruded from the vulva. Considerable shock ensued, and the fundus was wrapped in sterile gauze but not replaced. Three hours later it was irrigated with saline and pushed back into the vagina. Reposition of the uterus, which had involuted well, was carried out on Sept. 29th by means of Aveling's repositor, and was complete within 19 hours of its application. The repositor was removed from the uterine cavity after five minutes'gentle traction. On Oct. 4th patient appeared in good health; the fundus was normal in situation and contour, and no bleeding had occurred.

Dr. Barris added that the case presented several points of interest. It was an addition to those recently described by Dr. Herbert Spencer, ${ }^{1}$ and it emphasised the value of late reposition of the uterus, as practised by him. The case also illustrated the value of blood transfusion in marked anæmia. The third point of interest was the demonstration that Carrel's tubes could be used for sepsis during the puerperium witk no discomfort to the patient.

Discussion on Latent Syphilis during Pregnancy.

Papers on this subject were read by Dr. R. A. HENDRY, Dr. AMAND RoUTH, and Mr. JoHN ADAMS. These are published in full in this issue of THE LANCET.

In the course of the discussion Mr. CHARLEs GIBBs said that his 25 years' experience in charge of women and children at the London Lock Hospital had shown him how deplorable was the gross neglect in the treatment of syphilis in pregnant women until the last few years. A poor woman suffering the double burden of pregnancy and the disease could not gain admission 